\title{
A prospective study on the predictive value of CSF oligoclonal bands and MRI in acute isolated neurological syndromes for subsequent progression to multiple sclerosis
}

\author{
E Paolino, E Fainardi, P Ruppi, M R Tola, V Govoni, I Casetta, V C Monetti, E Granieri, \\ M Carreras
}

\begin{abstract}
A prospective study in patients with a clinical acute isolated brainstem or spinal cord disorder was undertaken. The aim was to evaluate the predictive value of IgG intrathecal synthesis (through the detection of oligoclonal bands in CSF) and MRI lesions at presentation, for the subsequent progression to multiple sclerosis. Forty four patients took part in this study: 22 had a brainstem disorder and 22 a spinal cord disorder. After a mean period of 26 (SD 22) months, 30 patients (68.2\%) developed clinically definite multiple sclerosis. The remaining 14 patients were followed up for more than seven years. Twenty six (59.1\%) patients had oligoclonal bands in CSF, with a sensitivity of $80 \cdot 0 \%$, specificity of $85 \cdot 7 \%$, and a predictive value of $92 \cdot 2 \%$. Magnetic resonance imaging showed disseminated white matter lesions in 22 patients $(50.0 \%)$, with a sensitivity of $60 \cdot 0 \%$, a specificity of $71 \cdot 4 \%$, and a predictive value of $81 \cdot 7 \%$. The difference between patients with multiple sclerosis and patients without the disease was statistically significant for the findings of an IgG intrathecal synthesis $(P<0.001)$. It was only borderline for the MRI findings $(P=0.052)$. Thus the detection of an intrathecal IgG synthesis at presentation seemed to be a better prognostic indicator of the progression to multiple sclerosis in patients affected by acute isolated brainstem or spinal cord syndromes.
\end{abstract}

$(\mathcal{F}$ Neurol Neurosurg Psychiatry 1996;60:572-575)

E Paolino

E Fainard

P Ruppi

M R Tola

V Govoni

I Casetta

V C Monetti

E Granieri

M Carreras

Correspondence to:

Dr Ezio Paolino, Neurologic Clinic of the University of

Ferrara, Corso della

Giovecca, 203, 44100

Ferrara, Italy.

Received 20 July 1995

and in final revised form

2 January 1996

Accepted 5 January 1996 cord lesions which are highly suggestive of the demyelinating white matter typical of multiple sclerosis. ${ }^{13-15}$

Studies so far carried out mainly concern patients with clinically definite multiple sclerosis or acute unilateral optic neuritis. ${ }^{16-18}$ Only a few report such a paraclinical diagnostic approach in monosymptomatic clinically suspected multiple sclerosis-namely, patients with isolated brainstem and spinal cord syndromes. Results indicate that half of these patients show typical CSF and MRI abnormalities and that more than two thirds of them have a progression to clinically definite multiple sclerosis. ${ }^{19-23}$ These studies are either based on short periods of clinical observation-generally less than two years-or they take into account, in the final evaluation, the paraclinical criteria to support the diagnosis of multiple sclerosis. ${ }^{24}$ This, however, may be misleading if the final aim is to evaluate the real impact and predictive value of CSF OCB and MRI findings in the early phases of multiple sclerosis.

To verify the progression to clinically definite multiple sclerosis of monosymptomatic brainstem and spinal cord syndromes in patients with suspected multiple sclerosis, we undertook a prospective study, seven years ago, to evaluate sensitivity, specificity and predictive value of CSF analysis and MRI, by using, as a reference mark, only clinical criteria. $^{25}$

\section{Patients and methods}

This study included 66 consecutive patients with a monofocal acute or subacute clinical lesion of the brainstem or spinal cord at the time of their first hospital presentation. The study was restricted to patients under 50 years of age. All neurological diseases other than clinically suspected multiple sclerosis were excluded by means of clinical and paraclinical tests. All underwent a CSF and MRI examination, performed within 15 days from the onset of neurological symptoms and signs and before modulator or suppressor immunotherapy was begun.

We excluded six patients because of inadequate paraclinical evaluation (refusal of lum- 
bar puncture or MRI).

Patients who were subsequently diagnosed as having clinically definite multiple sclerosis according to the McAlpine criteria, ${ }^{25}$ had a minimum of seven years of clinical follow up.

Twelve other patients were dropped from the study because their follow up was less than seven years. None of the patients with acute isolated unilateral or bilateral optic neuritis were included as it is difficult to be sure of the aetiology of this disorder basing the diagnosis only on clinical and paraclinical tests.

When acute intercurrent bouts did not occur, the patients did not require any urgent medical help, so we examined them regularly every three months and, if necessary, blood and CSF analysis and MRI were repeated (15 patients). In this way, we found another four patients without multiple sclerosis, who were dropped from the studied population. These patients were excluded because three were found to be affected, at follow up, by systemic lupus erythematosus, and one by cyanocobalamin deficiency which caused a subacute combined sclerosis. At the moment of inclusion their serological tests were negative and, therefore, these diagnoses were not suspected.

Thus only 44 patients fulfilled the inclusion criteria. Twenty two patients were affected by brainstem isolated syndromes and complained of diplopia, ataxia, and vertigo at the onset. Clinical signs were gaze palsies, nystagmus, cranial nerve impairment, and involvement of the cerebellum and long tract ascending and/or descending ways, indicating various typical complete or incomplete brainstem crossed syndromes. The remaining 22 patients, affected by spinal cord isolated syndromes, had either tetraparesis or triparesis, which often showed a Brown-Séquard syndrome at cervical or dorsal level and usually had an acute or subacute onset (from a few days to two weeks). No patient had a clear acute myelitis that could be shown by an adequate clinical evaluation of signs and symptoms and laboratory tests (positive or negative diagnostic findings).

Serum and CSF albumin and IgG concentration were assayed by a nephelometer method. To detect IgG OCB, we examined unconcentrated CSF and paired diluted serum on agarose isoelectric focusing followed by silver staining. Two or more definite bands in the $\gamma$ region were needed to diagnose an oligoclonal pattern. ${ }^{26}$

At presentation, all patients underwent brain and spinal cord MRI studies with a 0.5 Tesla Philips Gyroscan (double spin echo technique-TE 50 and $100 \mathrm{~ms}$; TR $2000 \mathrm{~ms}$ ).

Five $\mathrm{mm}$ contiguous axial and $4 \mathrm{~mm}$ sagittal slices were obtained in all the brain images. The spinal cord (cervical, thoracic, and lumbosacral) was generally investigated in the two major projections, whereas contiguous axial studies were performed only when a reasonable and pertinent diagnostic uncertainty was present. T2 weighted images were found to be more sensitive than $\mathrm{T} 1$ weighted images in detecting demyelinating lesions compatible with multiple sclerosis. The presence of three or more (multifocal) lesions in the cerebral white matter or in the spinal cord was considered to be strongly indicative of multiple sclerosis. We excluded lesions explaining the presenting syndrome from the MRI analysis.

Data from CSF and MRI were blind tested, and patients were divided into four groups according to the pattern found in the final clinical diagnosis: true positive (TP), false negative $(\mathrm{FN})$, true negative (TN), and false positive (FP), so that we were able to calculate sensitivity (TP/TP $+\mathrm{FN}$ ) and specificity $(\mathrm{TN} / \mathrm{TN}+\mathrm{FP})$. The predictive value (PV)the probability that a patient may have multiple sclerosis at follow up-was estimated from the formula:

$$
P V=\frac{P \times S}{(P \times S)+(1-P) \times(1-S p)}
$$

where $P$ is the prevalence of the disease in our series, $S$ is sensitivity, and $S p$ is specificity.

We also estimated the odds ratios (ORs) with the formula:

$\mathrm{OR}=\frac{\text { Group A NIS/MS }}{\text { Group B NIS/MS }} \times \frac{\text { Group B NIS only }}{\text { Group A NIS only }}$

where group A represents patients with neurological isolated syndromes (NIS) in the brainstem or spinal cord with CSF OCB and/ or disseminated MRI lesions at presentation, and group B shows those patients without CSF OCB or MRI lesions. "MS" and "only" represent the progression or otherwise to the disease.

Statistical evaluation was by Fisher's exact test.

\section{Results}

Forty four patients (13 males and 31 females; mean age at onset: 30.39 (SD 10.2) years) took part in this prospective study.

At presentation, there was an isolated brainstem syndrome in 22 patients and an isolated spinal cord syndrome in the other 22 . After a mean period of 26 (SD 22) months, 30 patients $(68 \cdot 2 \%)$ developed clinically definite multiple sclerosis. There were 11 males and 19 females, mean age at presentation $32 \cdot 1$ (SD 10.5) and at clinical diagnosis 34.3 (SD 11.3) years. The remaining 14 patients, two males and 12 females, without clinically definite multiple sclerosis, were followed up for a mean of 80 (SD 5) months.

All except two of the patients with an isolated brainstem syndrome developed clinical relapses outside the brainstem and were therefore classified as having clinically definite multiple sclerosis $(90.9 \%)$, whereas an initial spinal cord disorder evolving to clinically definite multiple sclerosis was found in only 10 patients $(45 \cdot 4 \%)$. The difference between isolated brainstem syndromes and isolated spinal cord syndromes evolving to clinically definite multiple sclerosis was statistically significant $(P<0.005$; table 1$)$.

Ten patients (33.3\%) developed clinically definite multiple sclerosis within one year, eight in the second year (total percentage = 
Table 1 Clinical and paraclinical features at presentation in patients with isolated brainstem or spinal cord syndromes

\begin{tabular}{|c|c|c|c|}
\hline Characteristics & Male patients & Female patients & Total \\
\hline $\begin{array}{l}\text { No of patients } \\
\text { Mean age (SD) (y) }\end{array}$ & $\begin{array}{l}13(29 \cdot 5) \\
31 \cdot 8(11 \cdot 5)\end{array}$ & $\begin{array}{l}31(74 \cdot 5) \\
29 \cdot 6(9 \cdot 6)\end{array}$ & $\begin{array}{l}44 \\
30 \cdot 3(10 \cdot 2)\end{array}$ \\
\hline $\begin{array}{l}\text { Brainstem isolated syndromes } \\
(22 / 44 ; 50 \cdot 0 \%)\end{array}$ & $7(31 \cdot 8)$ & $15(68 \cdot 2)$ & 22 \\
\hline $\begin{array}{l}\text { Spinal cord isolated syndromes } \\
(22 / 44 ; 50 \cdot 0 \%) \\
\text { Presence of CSF IgG OCB }\end{array}$ & $6(27 \cdot 3)$ & $16(72 \cdot 7)$ & 22 \\
\hline $\begin{array}{l}(26 / 44 ; 59 \cdot 1 \%) \\
\text { MRI detected disseminated cerebral }\end{array}$ & $7(26 \cdot 9)$ & $19(73 \cdot 1)$ & 26 \\
\hline $\begin{array}{l}\text { and spinal cord lesions }(22 / 44 ; 50.0 \%) \\
\text { Patients with progression to multiple }\end{array}$ & $11(50 \cdot 0)$ & $11(50 \cdot 0)$ & 22 \\
\hline $\begin{array}{l}\text { sclerosis }(30 / 44 ; 68 \cdot 2 \%) \\
\text { Patients with brainstem isolated }\end{array}$ & $11(36 \cdot 7)$ & $19(63 \cdot 3)$ & 30 \\
\hline & $7(35 \cdot 0)$ & $13(65 \cdot 0)$ & 20 \\
\hline $\begin{array}{l}\text { Patents with spinal cord isolated } \\
\text { syndrome and multiple sclerosis } \\
(10 / 22 ; 45 \cdot 4 \%)^{\star \star}\end{array}$ & $4(40 \cdot 0)$ & $6(60 \cdot 0)$ & 10 \\
\hline
\end{tabular}

Values in parentheses are \% (apart from mean age (SD))

$\star \star \mathrm{P}<0.005 ; 20 / 22(90.9 \%) v 10 / 22(45.4 \%)$

CSF IgG OCB = Cerebrospinal fluid immunoglobulin $\mathrm{G}$ oligoclonal bands.

Table 2 Number of patients with progression to multiple sclerosis at follow up compared by means of predictive value and the odds ratios (ORs) of CSF oligoclonal bands (CSF $O C B)$ and MRI disseminated lesions at presentation

\begin{tabular}{|c|c|c|c|c|}
\hline \multirow[b]{2}{*}{$\begin{array}{l}\text { Test and findings } \\
\text { at presentation }\end{array}$} & \multicolumn{4}{|c|}{ Outcome after a seven year follow up } \\
\hline & $\begin{array}{l}\text { Multiple sclerosis } \\
(n=30)\end{array}$ & $\begin{array}{l}\text { Non-multiple sclerosis } \\
(n=14)\end{array}$ & OR & $\begin{array}{l}\text { Predictive } \\
\text { value }\end{array}$ \\
\hline \multicolumn{5}{|l|}{ CSF OCB: } \\
\hline Positive ${ }^{\star \star \star}$ & 24 & 2 & \multirow{2}{*}{$\begin{array}{l}24 \\
(95 \% \mathrm{CI}=4 \cdot 2-137 \cdot 2)\end{array}$} & \multirow[t]{2}{*}{$92 \cdot 2$} \\
\hline Negative ${ }^{\star \star \star}$ & 6 & 12 & & \\
\hline $\begin{array}{l}\text { MRI lesions: } \\
\text { Positive`}^{\star}\end{array}$ & 18 & 4 & \multirow{2}{*}{$\begin{array}{l}3.7 \\
(95 \% \mathrm{CI}=0.9-14 \cdot 6)\end{array}$} & \multirow[t]{2}{*}{$81 \cdot 7$} \\
\hline Negative* & 12 & 10 & & \\
\hline
\end{tabular}

${ }^{\star} \mathrm{P}=0.052 ; 18 / 30(60.0 \%) v 4 / 14(28.6 \%)$

$\star \star \star \mathrm{P}<0.001 ; 24 / 30(80 \cdot 0 \%) v 2 / 14(14.3 \%)$

$60.0 \%$ ), and four in the third year (total percentage $=73 \cdot 3 \%$ ). The remaining eight who developed definite multiple sclerosis required a mean period of clinical observation of at least five years.

Twenty six (59.1\%) patients had CSF OCB and $22(50.0 \%)$ had MRI disseminated white matter lesions at initial presentation. If we refer these data to the 30 patients who developed a clinically definite multiple sclerosis, 18 of the patients with an isolated brainstem syndrome showed CSF OCB $(18 / 20 ; 90.0 \%)$ and a positive MRI was found in 13 patients $(13 / 20 ; 65.0 \%)$. Moreover, in patients with isolated spinal cord syndromes we found six CSF OCB $(6 / 10 ; 60.0 \%)$ and five MRI positive patients $(5 / 10 ; 50.0 \%$; table 1$)$. The difference, however, was not statistically significant for either of the tests.

Thus in total, 24 out of the 26 patients with CSF OCB $(92.3 \%)$ and 18 of those with disseminated lesions on MRI ( $81.8 \%)$ developed a clinically definite multiple sclerosis. There were two false positives for the CSF analysis and four for the MRI, and six and 12 false negatives respectively.

Therefore, we estimated a sensitivity of $80.0 \%$ and a specificity of $85.7 \%$ for CSF OCB, and a sensitivity of $60.0 \%$ with a specificity of $71.4 \%$ for MRI. The predictive value was $92.2 \%$ for the initial presence of CSF OCB and $81.7 \%$ for disseminated MRI lesions (table 2). The difference between patients with multiple sclerosis and those without was statistically significant only for the findings of an IgG intrathecal synthesis $(P<0.001)$ and not for the MRI $(P=0.052)$. These results were also confirmed by the ORs.

\section{Discussion}

In this study, we have found that a progression to clinically definite multiple sclerosis in patients affected by acute isolated neurological syndromes may be predicted early from CSF and MRI studies. Our results differ slightly from those reported elsewhere, ${ }^{19-23}$ as they are higher and statistically significant only for the evidence of CSF OCB $(P<0.001)$ and borderline for the MRI findings $(P=0.052)$.

In other studies ${ }^{27}{ }^{28}$ it is reported that MRI is the better predictor for the progression to multiple sclerosis. This may be because our study plan is in part different. Firstly, we did not include optic neuritis in the series as it is difficult to be sure of its aetiology when only clinical and paraclinical tests are used in its diagnosis. Secondly, we chose to consider the MRI abnormal only when three or more lesions in the cerebral white matter or in the spinal cord were present. On the other hand, the other studies ${ }^{27} 28$ confirm that this choice was correct as a higher rate of progression to multiple sclerosis was seen only when four or more MRI lesions were found at presentation.

In our series, half the patients had an isolated brainstem disorder and $90.9 \%$ of this half developed a clinically definite multiple sclerosis. The remaining $50 \%$ presented a spinal cord syndrome and only $45 \cdot 4 \%$ of these progressed to clinically definite multiple sclerosis, thus showing a highly significant difference $(P<0.005)$.

We know that, compared with cerebral MRI, spinal cord MRI has less resolution in showing adjunctive demyelinating lesions even if, sometimes, it may be useful for diagnosing other neurological diseases mimicking multiple sclerosis. On other hand, in many patients a definite intrathecal immunoglobulin synthesis may be found even in the first manifestation of the disease, in any isolated area involved, including the brainstem or spinal cord. ${ }^{1-12}$ 19-2329

However, test positivity of MRI and CSF analysis is similar in both brainstem and spinal cord syndromes. It is the greater rate of progression to multiple sclerosis of patients with an affected brainstem which determines a significant CSF OCB finding in comparison with the morphological analysis.

It must be noted that the CSF profile does not always give a clear picture for diagnostic purposes, even when performed on patients with clinically definite multiple sclerosis. In fact, quantitative and qualitative CSF pictures, in our experience, may vary in the different phases of the disease. In many patients we found a poor or scarcely definite CSF OCB pattern at onset. However, in the successive relapses that define the disease, CSF abnormalities give clearer patterns, which become more and more evident and remain unchanged for many years in the course of the disease. In the final or chronic stages, when the disease shows less clinical sharpness, the CSF profile may be similar to that at the onset, 
as if the intrathecal immunological reaction had exhausted itself. This could be related to a burning out phenomenon.

Because our series includes only cases at onset, this could account for the fact that CSF analysis did not reach greater expected predictive percentages in clinically suspected multiple sclerosis. Furthermore, in the initial phases of some systemic diseases a neurological disorder may possibly mimick multiple sclerosis, as we have shown recently. ${ }^{30}$

This work was supported by a grant of the Regione Emilia Romagna.

1 Laterre EC, Callewaert A, Heremans JF, Sfaello Z Electrophoretic morphology of gamma globulins in cerebrospinal fluid of multiple sclerosis and other diseases of brospinal fluid of multiple sclerosis and other

2 Link H, Mueller R. Immunoglobulins in multiple sclerosis and infections of the nervous system. Arch Neurol 1971, 25:326-34

3 Vandvik B, Skrede S. Electrophoretic examination of cerebrospinal fluid proteins in multiple sclerosis and other neurological diseases. Eur Neurol 1973;9:224-41.

4 Ebers GC, Paty DW. CSF electrophoresis in one thousand patients. Can $\mathcal{F}$ Neurol Sci 1980;7:275-80.

5 Kostulas VK. Oligoclonal IgG bands in cerebrospinal fluid. Methodological and clinical aspects. Acta Neurol Scand 1985;72(suppl 103):1-112.

6 Delpech B, Lichtblau E. Etude quantitative des immunoglobulines $\mathrm{G}$ et de l'albumine du liquide cèphalo-rachidien. Clin Chim Acta 1972;37:15-23.

7 Link H, Tibbling G. Principles of albumin and IgG analyses in neurological disorders. III. Evaluation of IgG synthesis within the central nervous system in multiple sclerosis. Scand 7 Clin Lab Invest 1977;37:397-401.

8 Tourtellotte WW, Ma BI. Multiple sclerosis: the bloodbrain-barrier and the measurement of the novo central nervous system IgG synthesis. Neurology 1978;28:76-83.

9 Tourtellotte WW, Potvin AR, Fleming JO, et al. Multiple sclerosis: measurement and validation of central nervous system IgG synthesis rate. Neurology 1980;30:240-4

10 Schuller E, Sagar HJ. Central nervous system IgG synthesis in multiple sclerosis: application of a new formula. Acta Neurol Scand 1983;67:365-71.

11 Reiber H, Felgenhauer K. Protein transfer at the blood cerebrospinal fluid barrier and the quantitation of the humosimune response within the central nervous system. Clin Chim Acta 1987;163:319-28.

12 Ohman S, Forsberg P, Vrethem M. An improved formula for the judgement of intrathecally produced IgG in the presence of blood-brain-barrier damage. Clin Chim Acta presence of blood-

13 Gebarski SS, Gabrielsen TO, Gilman S, et al. The initial diagnosis of multiple sclerosis: clinical impact of mag netic resonance imaging. Ann Neurol 1985;17:469-74.
14 Farlow MR, Markand ON, Edwards MK, Stevens JC, Kolar OJ. Multiple sclerosis: magnetic resonance imaging, evoked responses, and spinal fluid electrophoresis. Neurology 1986;36:828-31.

15 Giesser BS, Kurtzberg D, Vaughan HG, et al. Trimodal evoked potentials compared with magnetic resonance imaging in the diagnosis of multiple sclerosis. Arch Neurol 1987;44:281-4.

16 Frederiksen JL, Larsson HBW, Henriksen O, Olesen J. Magnetic resonance imaging of the brain in patients with acute monosymptomatic optic neuritis. Acta Neurol with acute monosymp

17 Sandberg-Wollheim M, Bynke H, Conqvist S, et al. A longterm prospective study of optic neuritis: evaluation of risk factors. Ann Neurol 1990;27:386-93.

18 Stadt D, Kappos L, Rohrbach E, Heun R, Ratzka M. Occurrence of MRI abnormalities in patients with isolated optic neuritis. Eur Neurol 1990;30:305-9.

19 Paty DW, Oger JJF, Kastrukoff LF, et al. MRI in the diagnosis of MS: a prospective study with comparison of clinical evaluation, evoked potentials, oligoclonal banding, and CT. Neurology 1988;38:180-5.

20 Gilmore RL, Kasarskis EJ, Carr WA, Norvell E. Comparative impact of paraclinical studies in establishing the diagnosis of multiple sclerosis. Electroencephalogr Clin Neurophysiol 1989;73:433-42.

21 Marti-Fàbregas J, Martinez JM, Illa I, Escartìn A. Myelopathy of unknown etiology. A clinical follow up and MRI study of 57 cases. Acta Neurol Scand 1989;80: and -60 .

22 Miller DH, Ormerod IEC, Rudge P, et al. The early risk of multiple sclerosis following isolated acute syndromes of the brainstem and spinal cord. Ann Neurol 1989;26:635-9.

23 Sharief MK, Thompson EJ. The predictive value of intrathecal immunoglobulin synthesis and magnetic resonance imaging in acute isolated syndromes for subsequent development of multiple sclerosis. Ann Neurol 1991;29:147-51.

24 Poser CM, Donald W, Paty W, et al. New diagnostic criteria for multiple sclerosis: guidelines for research protocols. Ann Neurol 1983,13:227-31.

25 McAlpine D. Multiple sclerosis: a re-appraisal. In: McAlpine D, Lumsden CE, Acheson ED, eds. The problem of diagnosis. Edinburgh: Churchill Livingstone, 1972: lem of diagni.

26 Delmotte P, Gonsette R. Biochemical findings in multiple sclerosis. IV. Isoelectric focusing of the CSF gamma globulins in multiple sclerosis (262 cases) and other neurological diseases (272 cases). $\mathcal{f}$ Neurol 1977;215:27-37.

27 Lee KH, Hashimoto SA, Hooge JP, et al. Magnetic resonance imaging of the head in the diagnosis of multiple sclerosis: a prospective 2-year follow up with comparison of clinical evaluation, evoked potentials, oligoclonal banding, and CT. Neurology 1991;41:657-60.

28 Morrissey SP, Miller DH, Kendall BE, et al. The significance of brain magnetic resonance imaging abnormalities at presentation with clinically isolated syndromes suggestive of multiple sclerosis. A 5-year follow up study. Brain 1993;116:135-46.

29 Moulin D, Paty DW, Ebers GC. The predictive value of cerebrospinal fluid electro-phoresis in 'possible' multiple cerebrospinal fluid electro-phoresis

30 Tola MR, Granieri E, Caniatti L, et al. Systemic lupus erythematosus presenting with neurological disorders. $\mathcal{F}$ Neurol 1992;239:61-4. 